\title{
Influence of Drake Passage oceanography on the parasitic infection of individual year-classes of southern blue whiting Micromesistius australis
}

\author{
D. J. Agnew ${ }^{1, *}$, T. R. Marlow ${ }^{1}$, K. Lorenzen ${ }^{1}$, J. Pompert ${ }^{2}$, R. C. Wakeford ${ }^{1}$, \\ G. A. Tingley ${ }^{1,3}$
}

${ }^{1}$ Renewable Resources Assessment Group, Imperial College, Prince Consort Road, London SW7 2BP, United Kingdom
${ }^{2}$ Fisheries Department, PO Box 598, Stanley, Falkland Islands

${ }^{3}$ Present address: Centre for Environment, Fisheries \& Aquaculture Science, Pakefield Road, Lowestoft NR33 0HT, United Kingdom

\begin{abstract}
Southern blue whiting Micromesistius australis occurs around the southern coasts of South America and has been known to undertake summer feeding migrations to the Antarctic Peninsula and South Orkney Islands. The largest stock spawns to the southwest of the Falkland Islands and has been the subject of a major fishery on the Patagonian Shelf since 1978. Fish are infected with cysts of the Myxosporean parasite Kudoa alliaria which make the flesh commercially unattractive for fillets. A 10 yr study initiated in 1989 established that prevalence of the parasite is over $80 \%$ for fish older than $1 \mathrm{yr}$, and that average infection intensities are about 14 cysts per fish. We constructed a combined generalised linear/generalised additive model (GLM/GAM) of parasite abundance in M. australis. The combination of up to 30 ages and $8 \mathrm{yr}$ of data spanning $10 \mathrm{yr}$ allowed us to investigate rates of parasitism in 33 individual cohorts. Strong age and cohort effects in the model implied that the fish acquire parasites in their first 1 to $1 \frac{1}{2} \mathrm{yr}$ of life and that parasite abundance is set at these ages for the lifetime of the cohort. Several cohorts have statistically significantly lower parasite abundance than the majority, and these instances are roughly coincident with the 7 yr periodicity of seaice and sea surface temperature (SST) fluctuations in the Drake Passage. There are significant correlations between SST in the Drake Passage, the duration of sea-ice around Signy Island (South Orkney Islands) with a 1 yr time lag and parasite abundance in a cohort. We hypothesise that these correlations represent changes in the distribution and density of adult $M$. australis in warm and cold years, which thereby influences the density of the parasite field that juvenile fish encounter.
\end{abstract}

KEY WORDS: Micromesistius australis · Southern blue whiting $\cdot$ Kudoa alliaria Parasite density · Southwest Atlantic · Drake Passage

Resale or republication not permitted without written consent of the publisher

\section{INTRODUCTION}

Micromesistius australis (southern blue whiting) is an important commercial species fished primarily on the southern Patagonian shelf around and to the southwest of the Falkland Islands, but also around the tip of South America into Chilean waters (FAO 2000, Wöhler et al. 2000, S. D. Hill, D. Agnew, R. Wakeford, D. Middleton, A. Arkhipkin unpubl.). The fish form dense spawning aggregations to the southwest of the Falkland Islands (see Fig. 1) in September and October each year (Agnew 2002). The species was studied by Russian and Polish scientists in the 1960s and 1970s, both on the Patagonian shelf and in the Antarctic peninsula where it feeds on summer concentrations of krill, Euphausia superba (Shust 1978).

Micromesistius australis exhibits a high prevalence of infection with a Myxosporean tissue parasite (Grabda 


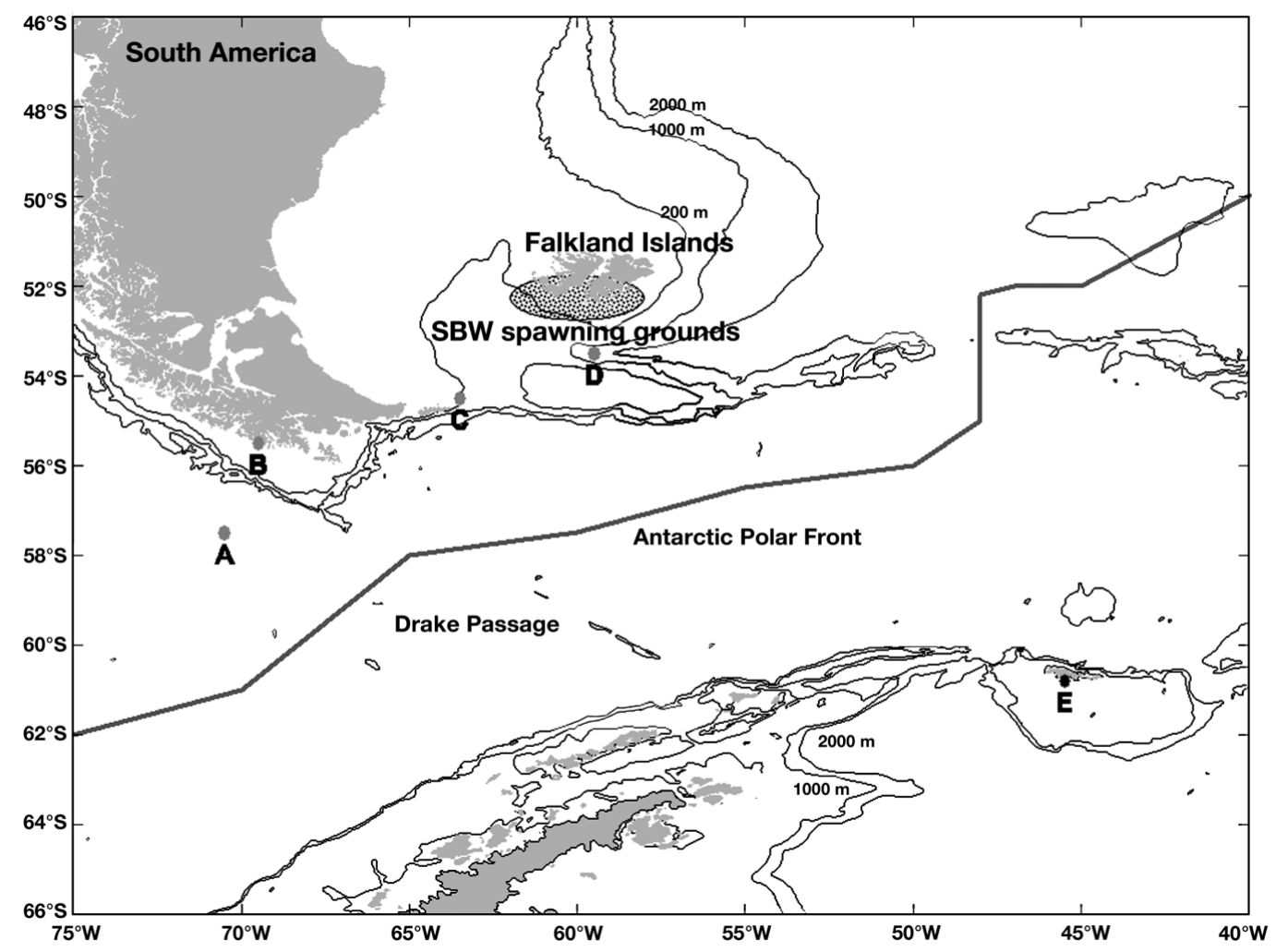

Fig. 1. Southwest Atlantic showing the locations used for calculating average quarterly sea surface temperatures (A to D) and seaice duration at Signy (E). Indicative positions are shown for the Antarctic Polar Front after Moore et al. (1999) and the southern blue whiting (SBW) spawning area

1978). Kovaljova et al. (1979) identified the species as Kudoa alliaria Schulman and Kovaljova, 1979 and reported prevalence in $M$. australis between 70 and $100 \%$ with intensities in individual fish of up to 56 cysts. Gaevskaya \& Kovaljova (1991) ${ }^{1}$ report similar levels of prevalence and intensities up to 65 cysts per fish in studies between 1971 and 1985. The parasite occurs as plasmodia containing 1 to 8 spores, each plasmodium being surrounded by host connective tissue forming a macroscopic pseudocyst (hereafter termed cyst) of $10 \mathrm{~mm}$ by 3 to $5 \mathrm{~mm}$ in size (Kovaljova et al. 1979). These authors list 3 other host species (Patagonotothen ramsayi, Notothenia conina, Macruronus magellanicus); however, other Kudoa species have been reported from various hosts from the Patagonian shelf (MacKenzie \& Longshaw 1995, Sardella \& Timi 1996, Kalavati et al. 2000).

Although it is not pathogenic to mammals (Ganowiak 1985), the large number of cysts in the muscle

${ }^{1}$ The handbook on the principal diseases and parasites of food fish from the Atlantic Ocean. Kaliningrad (available at www.ibss.iuf.net/people/gaevsk/kudall.html) tissue render the flesh unsightly and unacceptable to most consumers without substantial processing as well as causing post-mortem muscle degeneration or 'soft flesh' which reduces market value (Moran et al. 1999). Consequently, the main fishery for Micromesistius australis is now for processing as surimi (e.g. crab sticks) and fish meal. Recognising that the high levels of prevalence were potentially damaging for the fishery, the Falkland Islands Fisheries Department initiated research into the interaction between Kudoa alliaria and M. australis in the late 1980s.

\section{METHODS}

Following an intensive study carried out in 1987 and 1988, a sampling protocol was established which was carried out over the subsequent 10 yr (1989 to 1998). Approximately 400 to 600 fish were sampled randomly each year, by a number of observers, mostly from the catch of vessels fishing on the spring spawning aggregations to the southwest of the Falkland Islands. Two fillets from each fish were taken and frozen. Onshore, 
fillets were defrosted in lukewarm water and any dorsal fin material was removed. Each fillet was weighed and the number of parasite cysts in each of the fillets was counted with the aid of through-fillet illumination. Otoliths were sent to the Fisheries Research Laboratory in Gdynia, Poland for age determination. Data from 1993 and 1994 were omitted from the analysis owing to the inconsistency of the ageing for these 2 sampling years. Therefore, a total of 3538 fish were sampled from August to November over the 8 yr of the main study (1989 to 1992, 1995 to 1998). Only 75 of these $(2 \%)$ were older than $18 \mathrm{yr}$. Moreover, as the period progressed, fewer old fish were encountered (in $1989,7 \%$ were older than 18 , compared to none in 1998). This corresponds with a decline in the number of older age classes observed in the population as the fishery has progressed.

The number of cysts expected in each fish was modelled using a combination of generalised linear and additive models (GLM/GAM) in S-Plus v4.5. Such systems have been modelled in other species by a negative binomial, a 2-stage model using Poisson and $\gamma$ distributions (Maravelias 1997). This was investigated for our data using the Venables and Ripley S-Plus MASS library (Venables \& Ripley 1997), but the error structure of the resultant model was not normally distributed. An alternative approach was based on the 2 component solution to a $\delta$ distribution (Stefánsson 1996). The 2 components of the model were the chance of a fish being infected (prevalence) and the number of cysts in infected fish (intensity). The use of the terms prevalence, intensity and abundance follow the recommendations of Bush et al. (1997). Using the models, the prevalence or intensity of expected infection was predicted for various cohorts, ages and sampling years, and the overall parasite abundance was predicted by multiplying intensity by prevalence. Confidence intervals were calculated by multiplying SE by 1.96 .

A different combination of scientists and scientific observers undertook the study each year over the 10 yr study and a sampling year factor was used to correct for this. The fleet fishing pattern also changed during this time. Initially, fishing was directed at spawning concentrations to the southwest of the Falkland Islands in August to October. This fishery for fillets and headed and gutted fish was replaced towards the end of the study by surimi-producing trawlers, fishing later in the year in areas southwest and northeast of the Islands. An 'area' factor was therefore introduced into the model. Although some fish were sampled from the first half of the calendar year, the majority (94\%) were sampled from August to November. The analysis was restricted to these months to avoid the confounding effects of study year, age and cohort.
Assessments of this stock are routinely carried out by scientists at Imperial College (UK) and INIDEP (Instituto Nacional de Investigación y Desarrollo Pesquero, Argentina), based on shared data exchanged under the auspices of the Scientific Subcommittee of the bilateral South Atlantic Fisheries Commission. Catch at age data from the start of the fishery to 1987 were obtained from Csirke (1987). More recent data derive from the Argentine-UK data exchange. Other data required for the VPA were also available from those 2 sources, including weight at age, maturity and selectivity. The VPA was tuned by finding the fishing mortality for fully selected fish in the terminal year that minimised combined sums of squared differences between observed and expected log catch per unit effort (CPUE) data. CPUE series used were for surimi, Polish and Falklands vessels in Falklands waters, and a standardised Argentine CPUE (see Cordo \& Wöhler 2000, Wöhler et al. 2000) using, for each series, the equation:

$$
\ln \left(\hat{u}_{i}\right)=q_{i} \ln (B)
$$

where $\hat{u}$ is the expected catch per unit effort, $B$ is spawning stock biomass and $q$ is the catchability of fleet $i$. A similar assessment is described in more detail in Wöhler et al. (2000). In accordance with past practice, a value for natural mortality $(\mathrm{M}=0.15)$ was assumed, fish were assumed to be fully selected by the fishery at Age 10, and Age 21 included ages above.

Infection rates were investigated in relation to several environmental data series. Data on the winter duration of fast ice at Signy Island were obtained from the British Antarctic Survey (BAS). These data are calculated from the difference between the day that sea-ice arrived at Factory Cove, Signy Island, and the day that sea-ice finally departed, corrected for any periods in the spring when ice left the cove only to re-enter it again (Murphy et al. 1995, E. J. Murphy pers comm.). Monthly sea surface temperature (SST) data on a $1^{\circ}$ grid from 1981 to 2000, prepared at the National Centers for Environmental Prediction and National Climatic Data Center by Dick Reynolds, Diane Stokes and Tom Smith, were obtained from the University Corporation for Atmospheric Research's Data Support Section (http:// dss.ucar.edu/datasets/). The El Niño Southern Oscillation (ENSO) index is defined as the normalised pressure difference between Tahiti and Darwin and the series, based on the method given by Ropelewski \& Jones (1987), was obtained from the Climatic Research Unit at the University of East Anglia, UK (www.cru.uea.ac.uk/cru/data/soi.htm). For each year, an average of monthly values from July to September was taken. 


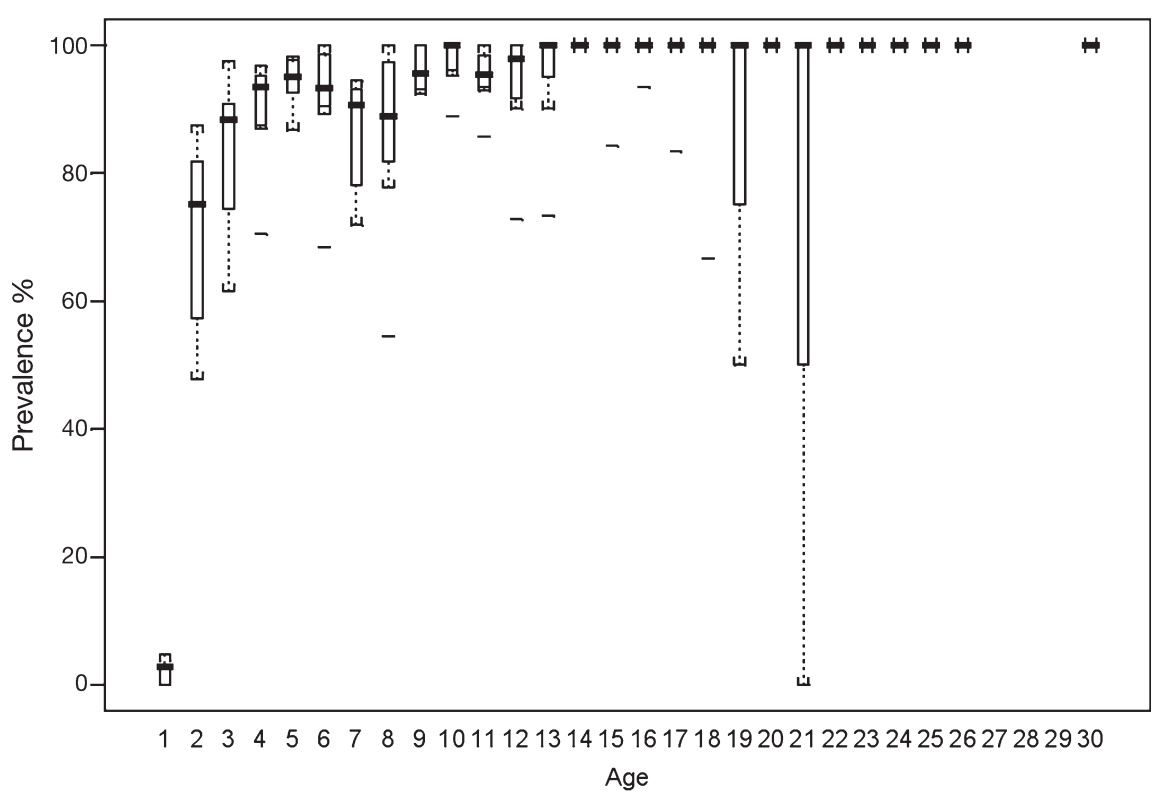

Fig. 2. Micromesistius australis. Prevalence of infection with Kudoa alliaria cysts by age

\section{RESULTS}

\section{Prevalence and intensity of infection}

Sites of infection in the muscles of Micromesistius australis contained between 1 and 4 cysts. During the intensive study in 1987 to 1988, in which 2496 fish were examined, an estimated $60 \%$ of sites consisted of 4 cysts, $10 \%$ of $3,19 \%$ of 2 and $11 \%$ of 1 cyst. The mean length of cysts increased with age of the fish, from $2.6 \mathrm{~mm}$ in fish Age 1 to $8.7 \mathrm{~mm}$ in fish Age 7 , beyond which there was no further growth. Small cysts are difficult to detect, so the intensity and prevalence recorded for young fish may be underestimated.

Prevalence of infection with $\mathrm{Ku}$ doa alliaria cysts increased rapidly up to Age 6 (Fig. 2), although there appeared to be a small drop in prevalence at Ages 7 and 8, while intensity increased at a steadier rate (Fig. 3). Almost all the population was infected at Age 3. The number of cysts per individual fish (intensity) rose continuously until Age 6, rose gradually again until Age 12 and then declined slowly. The variance:mean ratios for the number of cysts per fish, calculated for each year of the study, are between 3 and 40. However, Fig. 3 shows that the number of fish with very high numbers of parasites drops from about Age 12. The decline is most marked in fish over Age 18, when sample sizes become very small. This is unlikely to reflect decreasing parasite numbers in individual fish, but is a real population effect the possible causes of which are discussed later.

\section{Cohort-specific variability in parasite numbers}

Prevalence was modelled as a binomial GAM on presence/absence, using the S-Plus spline function on age, and cohort and sampling year as factors. The age spline followed the shape of Fig. 2 and was not easily approximated by a polynomial or other function. As the confidence intervals around the age spline and especially the cohort factor were small, the model was left as a GAM. This precluded calculation of standard errors, since these are only available in S-Plus for parameter combinations that are represented in the data, but as the confidence intervals are small it was a reasonable compromise within the overall model. The final model explained $36 \%$ of the residual deviance.

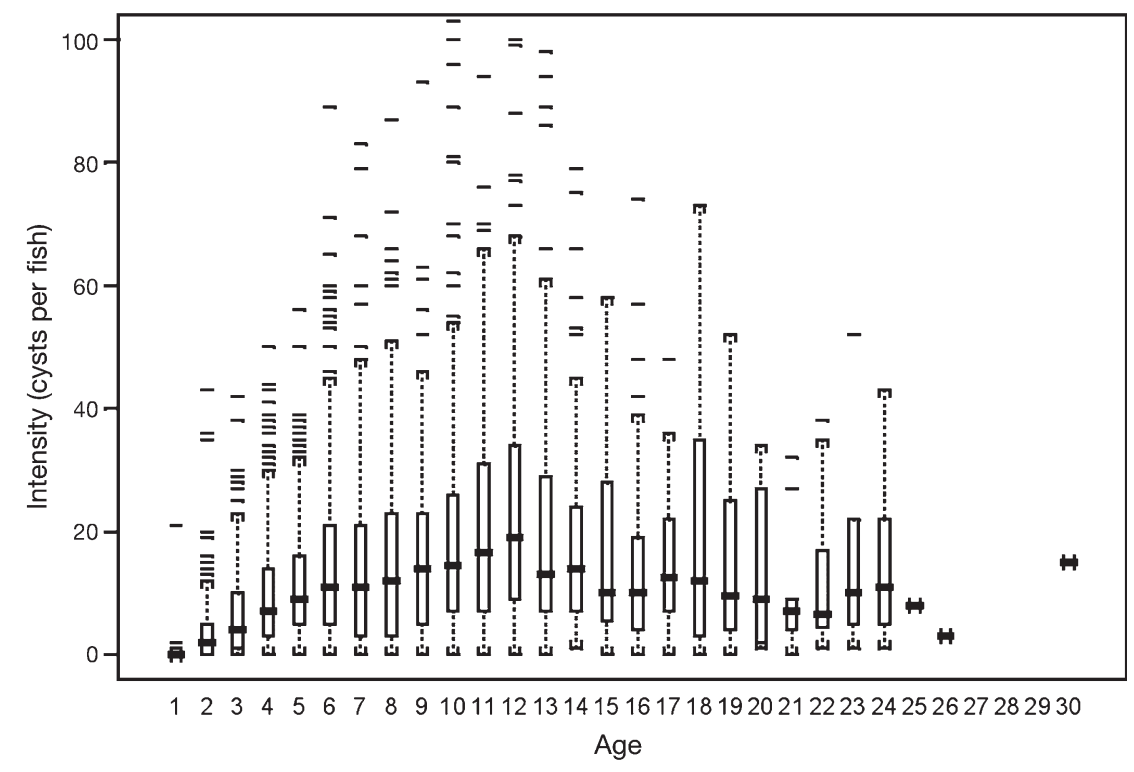

Fig. 3. Micromesistius australis. Intensity of infection with Kudoa alliaria cysts by age 
Infection intensity is log-normally distributed (Fig. 3), so a simple Gaussian model was constructed around $\ln$ (number of cysts per fish). Preliminary trials demonstrated that a fourth-order polynomial function on age effectively reproduced the spline function fit by an exploratory GAM. Accordingly, a GLM was constructed, and significant factors were found to be the fourth-order polynomial on age, the year in which the fish were sampled, and the cohort to which they belonged. Sex and the area from which they were sampled (NE or SW of the Falkland Islands) did not explain significant amounts of the variance $(p>0.05)$. The only interaction term that showed any sign of being significant was between age and cohort. However, stepwise analysis demonstrated that the Akaike Information Criterion (AIC) was minimised when the model had no interaction terms. The final model was therefore a GLM of the following form:

$\ln$ (number of cysts per fish) fourth-order polynomial on age + sampling year + cohort

where sampling year and cohort were treated as factors. The resultant GLM had a normal error structure, and explained $21 \%$ of the residual deviance.

Although sampling year was a significant factor in the models, it is assumed that this is primarily due to an observer effect because there was no consistent trend in the sampling year factor over time. Gaevskaya \& Kovaljova $(1991)^{1}$ report no seasonal or annual variability in infection in their 1971 to 1985 study. The 2 models were combined to predict the expected number of cysts in fish of Ages 1 to 18 and cohorts 1973 to 1996 , for a nominal sampling year of 1995. The predicted intensity in each of these combinations of age and cohort was estimated from the GLM, which in S-Plus yields $95 \%$ confidence intervals. This was multiplied by the prevalence predicted for that age and cohort by the GAM model.

The predicted intensity of infection is cohort-specific (Fig. 4). For the cohorts born between 1975 and 1992, there is an overall average parasite loading of about 14 cysts per fish, interspersed with 4 periods in which parasite loading was lower (1976 to 1977,1981 to 1992 , 1988 to 1989 and 1995 to 1996 at the end of the series). The standard errors of the predictions increased markedly for cohorts born earlier than 1976, and later than 1995, an expected result given the low sample sizes for these cohorts (less than 30 fish). There is significant autocorrelation in this series, with a lag of $1 \mathrm{yr}$, and a second autocorrelation peak at a lag of $7 \mathrm{yr}$.

The considerable uncertainty in model predictions of parasite infection rates for cohorts earlier than 1975 is exacerbated by the lack of information in the data
Table 1. Micromesistius australis. Mean abundance of Kudoa alliaria cysts from cohorts earlier than 1975

\begin{tabular}{|lrrc|}
\hline Cohort & Mean & $\mathrm{n}$ & $\mathrm{SD}$ \\
\hline 1964 & 8.0 & 1 & \\
1965 & 16.0 & 3 & 5.57 \\
1966 & 13.0 & 2 & 4.24 \\
1967 & 16.1 & 18 & 15.91 \\
1968 & 12.1 & 8 & 10.51 \\
1969 & 10.7 & 10 & 8.98 \\
1970 & 16.0 & 5 & 16.93 \\
1971 & 17.0 & 6 & 12.93 \\
1972 & 24.5 & 13 & 46.02 \\
1973 & 19.3 & 21 & 34.02 \\
1974 & 22.0 & 23 & 16.06 \\
& & & \\
\hline
\end{tabular}

for the GLM/GAM model to separate age- and cohort-effects. The spline or polynomial fit to age within each model is peaked at Age 12, with the model predicting that older ages have fewer parasites. This is consistent with Fig. 3, but the polynomial tends to overestimate the age effect for ages greater than 14. This, together with the lack of data on pre-1975 cohorts, precludes using the model to estimate the cohort effect for cohorts prior to 1975 (the 1975 cohort was Age 14 in the 1989 sampling year). Taking simple means of the number of cysts in each of the cohorts earlier than 1974, allows us to obtain series of parasite incidence that are not standardised for age- and sampling year-effects, and are not therefore directly comparable with those in Fig. 4. However, they do show general trends, with relatively high numbers of parasites in cohorts from the start and end of the series and relatively low numbers in cohorts 1968 and 1969 (Table 1).

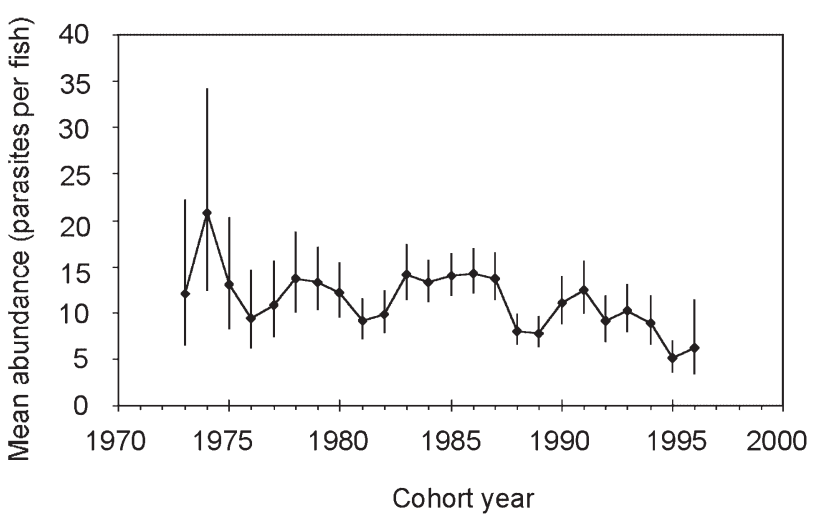

Fig. 4. Micromesistius australis. Mean abundance of parasites Kudoa alliaria in fish of Age 7 to 14 (showing 95\% confidence limits) predicted by the combined generalised linear/ generalised additive model (GLM/GAM) of prevalence and intensity, standardised for the 1995 sampling year. The $x$-axis is the year of birth of the cohort 
(a)

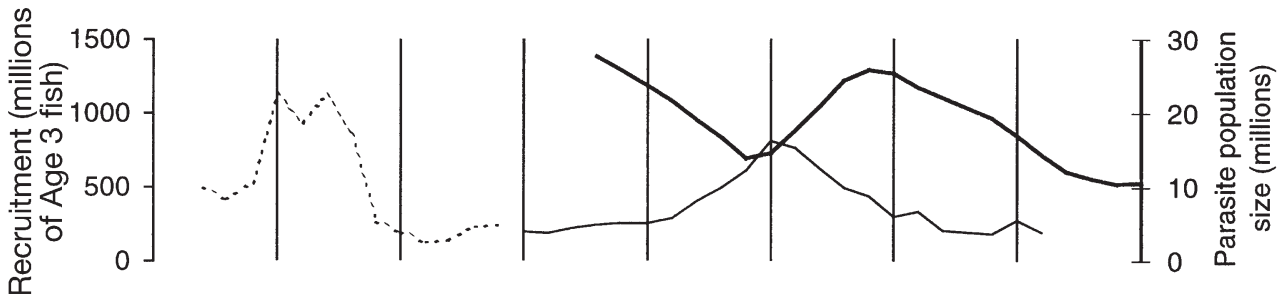

(b)

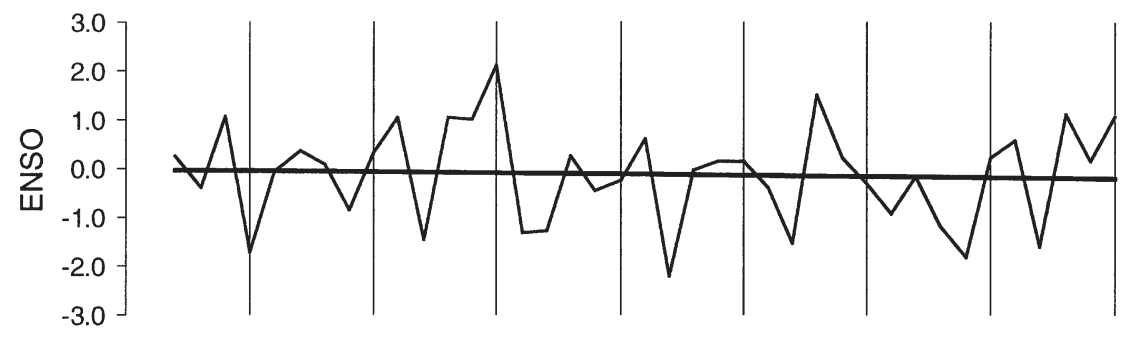

(c)
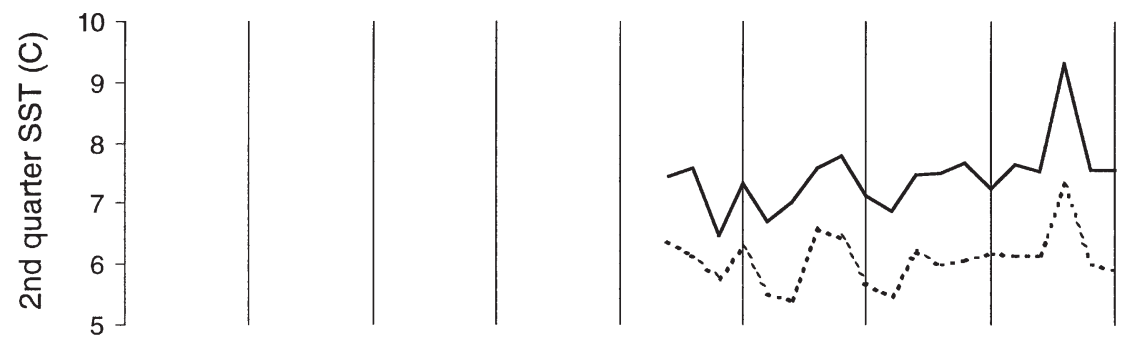

(d)

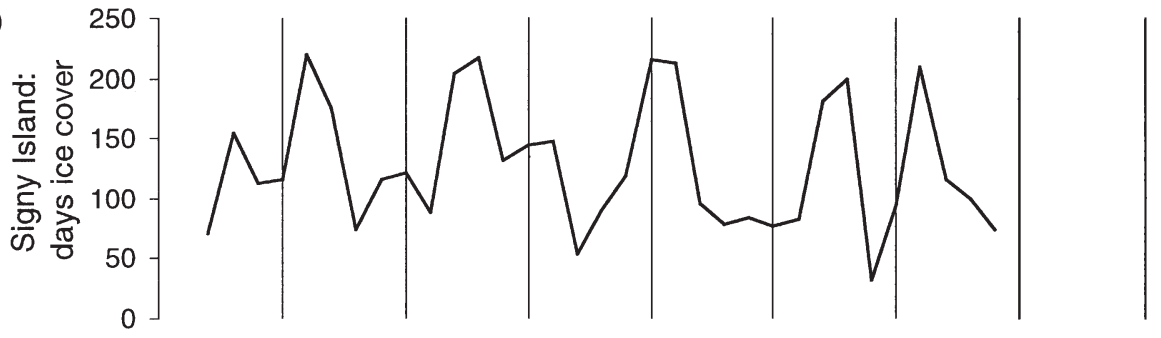

(e)

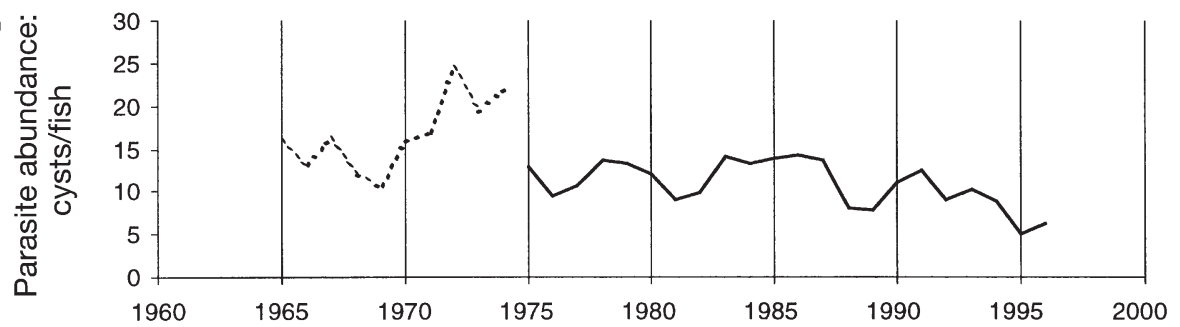

Fig. 5. Micromesistius australis infested by Kudoa alliaria. Trends in population, environmental and parasite parameters. (a) Host recruitment at Age 3 (left axis) plotted against cohort year; thin solid line is from the virtual population analysis (VPA), dotted line is historical recruitment projected backwards from the VPA assuming natural mortality of $0.15 \mathrm{yr}^{-1}$. Parasite population size (right axis), obtained by multiplying host population size at age with age- and cohort-specific parasite abundance predicted from the combined generalised linear/generalised additive model (GLM/GAM) standardised at observation year 1995, plotted against year of the population estimate (thick solid line). (b) ENSO index (July to September average). (c) Sea surface temperature in the second quarter of the year from the northwest Drake Passage (dotted line) and Isle de Fonso (solid line). (d) Duration of winter sea-ice at Signy Island, plotted unlagged against year. (e) GLM/GAM predicted parasite density at host Ages 7 to 14 standardised for observation year 1995 (solid line), plotted against cohort year; backward projection of parasite abundance from simple means given in Table 1 (dotted line) 


\section{Correlates of cohort-specific parasitic infection rates}

The VPA provided estimates of numbers at age in the host population from 1978 to 2000. Numbers at Age 3 were used as an index of cohort size, because fish do not recruit to the fishable stock until Ages 2 or 3 . Rather than calculate host population biomass, we chose to express host population size in terms of the total number of parasites present in the population at any one time. For each age in a year of the assessment, the GLM/GAM model was used to predict the mean abundance (cysts per fish) that would be expected for that age, taking into account the cohort to which fish of that age belonged. Where the model was unable to predict the mean abundance (for cohorts earlier than 1975 or later than 1996), the mean abundance for that age for all years was substituted. Ages greater than 18 were assumed to have the same mean abundance as Age 18.

The catch at age matrix provided by Csirke (1987) for the first year of significant catches of Micromesistius australis on the Patagonian shelf contains sufficient information to allow some projection of the size of earlier cohorts. With reasonable assumptions about the distribution of size at age in the unexploited population, it might also be possible to extend the estimates of biomass to times prior to 1978. However, the time series of cohort strengths shows that there have been 2 periods in the last $40 \mathrm{yr}$ when recruitment has been high — 1965 to 1968 and 1983 to 1987 and the rest of the time recruitment has been low. With such highly variable recruitment dynamics, any projection backwards of the VPA would require a stochastic approach, which is outside the scope of this study.

The time series of environmental data are somewhat limited by availability. SST is available only from 1982. We extracted it from 4 locations between the Northwest Drake Passage and the Falkland Islands (Fig. 1). Data on the duration of fast ice at Signy Island are available from the late 1940s up to 1993 when BAS closed the base to overwintering operations.

The most significant series are shown in Fig. 5. There are 5 periods of low parasite abundance (1968 to 1969, 1976 to 1977,1981 to 1982,1988 to 1989 and 1995 to 1996). These are coincident with warm periods associated with a short duration of fast ice cover at Signy Island over winter and warm SSTs in the northern Drake Passage. There is a remarkable coincidence between low parasite abundance for a cohort and periods of restricted sea-ice duration at Signy Island the year after the cohort was born. Significant pairwise correlations with parasites between sea-ice $(r=0.484)$ and SST in the northern Drake Passage $(r=-0.579)$ are apparent when the Signy Island data are lagged by 1 yr (Table 2). Connectivity between oceanographic events around the southern tip of South America, parasite abundance and sea-ice at Signy Island the following year are consistent with the rate of progression of the Antarctic Circumpolar Wave. This moves 36 to $45^{\circ}$ eastwards per year (White \& Peterson, 1996), and is indicated strongly by the Signy sea-ice data (Murphy et al. 1995).

There is little relationship between parasite abundance and host population size or fish stock recruitment, except perhaps in the most recent years where the decline in parasite abundance is coincident with the decline in the stock size. This decline is also coincident with a period of warm oceanographic conditions. There is no significant correlation between the ENSO index and parasite abundance, although there is some coincidence between the occurrence of some of the recent El Niño events (1976 to 1977, 1982 to 1983, 1986 to 1987,1991 to $1992,1993,1994$ and 1997 to 1998) and the declines in parasite abundance.

Table 2. Pearson's correlation coefficients for combinations of Signy ice duration, sea surface temperature (SST) and parasite abundance in a cohort year. Scatter plots confirmed that there were generally linear relationships between parasite abundance and these environmental covariates. SST is followed by a suffix indicating the location and longitude (see Fig. 1) and the time of year, where $q=$ quarter. Values in bold are significant $(p<0.05)$

\begin{tabular}{|lrcc|}
\hline & $\begin{array}{c}\text { Parasites at } \\
\text { cohort year }\end{array}$ & $\begin{array}{c}\text { Signy ice } \\
\text { duration }\end{array}$ & $\begin{array}{c}\text { Signy ice duration } \\
\text { at year } t+1\end{array}$ \\
\hline Parasites at cohort year & 1.000 & & \\
Signy ice duration & -0.047 & 1.000 & \\
Signy ice duration & $\mathbf{0 . 4 8 4}$ & 0.153 & 1.000 \\
at year $t+1$ & & & \\
SST-A 70 q1 & -0.157 & -0.433 & -0.239 \\
SST-A 70 q2 & $-\mathbf{0 . 5 7 9}$ & -0.288 & $\mathbf{- 0 . 7 5 5}$ \\
SST-A 70 q3 & -0.410 & $-\mathbf{0 . 5 8 3}$ & $-\mathbf{0 . 6 1 6}$ \\
SST-A 70 q4 & 0.022 & -0.336 & -0.245 \\
SST-B 69 q1 & -0.419 & -0.359 & -0.029 \\
SST-B 69 q2 & $-\mathbf{0 . 5 6 7}$ & -0.239 & -0.448 \\
SST-B 69 q3 & -0.320 & -0.150 & $-\mathbf{0 . 5 7 9}$ \\
SST-B 69 q4 & -0.173 & -0.372 & -0.443 \\
SST-C 63 q1 & 0.142 & -0.465 & -0.156 \\
SST-C 63 q2 & -0.097 & -0.381 & -0.462 \\
SST-C 63 q3 & 0.041 & -0.121 & -0.150 \\
SST-C 63 q4 & 0.026 & -0.222 & -0.299 \\
SST-D 59 q1 & 0.226 & -0.389 & -0.035 \\
SST-D 59 q2 & -0.064 & -0.435 & -0.264 \\
SST-D 59 q3 & -0.216 & -0.383 & 0.029 \\
SST-D 59 q4 & -0.053 & -0.188 & -0.354 \\
& & & \\
\hline
\end{tabular}


The relationship between oceanographic conditions and parasite abundance are represented in Table 2 by correlation coefficients for SST and sea-ice (both unlagged and lagged) against parasite abundance. The parasite data are presented both by birth (cohort) year and lagged by 1 yr (so that the environmental data correspond to the year in which the hosts are $1 \mathrm{yr}$ old). There is a significant autocorrelation in parasite abundance with a 1 yr lag, which reflects the observation in Fig. 4 that years of low abundance appear to occur in twos. The correlation between parasite abundance and Signy sea-ice duration the year after the cohort was born is significant ( $p<0.05$ ), as are the correlations between SST in Quarter 2 (April to June), parasite abundance and sea-ice duration; however, this is only true for the northern Drake Passage water immediately south of the continent. There are no significant correlations between SST at Staten Island or the Falkland Islands and parasite abundance, either for the year of host birth or the year after birth. The correlations between SST and parasite abundance are quite specifically for the winter period; the highest correlations are found in April and May.

The significance of the Signy Island data lies not in their direct correlation with parasite abundance, but in their availability from 1947 compared to the SST data that only extend from 1982 to the present. The overlap period of the Signy and SST data is only 12 out of the $22 \mathrm{yr}$ of predicted data of parasite abundance, which diminishes their power in a multiple regression. A combined model, fitted by minimising least squares and utilising the complete time series of both the Signy Island sea-ice data and the SST data, naturally follows the Signy Island data (Fig. 6), but explains a significant $45 \%$ of the variance in parasite abundance (ANOVA, $\mathrm{p}<0.01$; residuals from the model were normally distributed).

The combined model (Fig. 6) generates predictions of parasite abundance for 22 cohorts of Micromesistius australis. However, this combined model uses the GLM/GAM predicted parasite abundance, whereas it is useful to examine the influence of these environmental covariates on the GLM and GAM themselves. This requires the use of a data set for which both environmental covariates that we have identified above (SST and Signy Island sea-ice) are available, and this is necessarily a more restricted period than used in the original GLM/GAMs (12 cohort years, 1982 to 1993; see Fig. 5). Nevertheless, this temporally restricted data set was used to add environmental covariates to the GLM/GAM models.

For the GAM on prevalence, the addition of SST (Quarter $2 \mathrm{SST}$ at $70^{\circ} \mathrm{W}$ ) and Signy Island ice along with the removal of cohort as a factor in the model significantly reduced the explained deviance from 27 to $25 \%$. These figures are lower than the $36 \%$ quoted above for the GAM because the latter model used a more restricted data set than the former. Conversely, for the GLM model of infection intensity the environmental data was able to account for cohort-dependent variance. Two models, one with SST at $70^{\circ} \mathrm{W}$ added to the previous GLM and the other also with SST at $70^{\circ} \mathrm{W}$ but without a cohort factor, explained 20.2 and $19.6 \%$ deviance and were not significantly different (ANOVA, $p>0.05$ ). Stepwise AIC selection demonstrated that $\mathrm{SST}$ at $70^{\circ} \mathrm{W}$ contained all the environmental information (as we would expect from the high correlation of these 2 data sets, no additional information was contained in the Signy Island ice data).

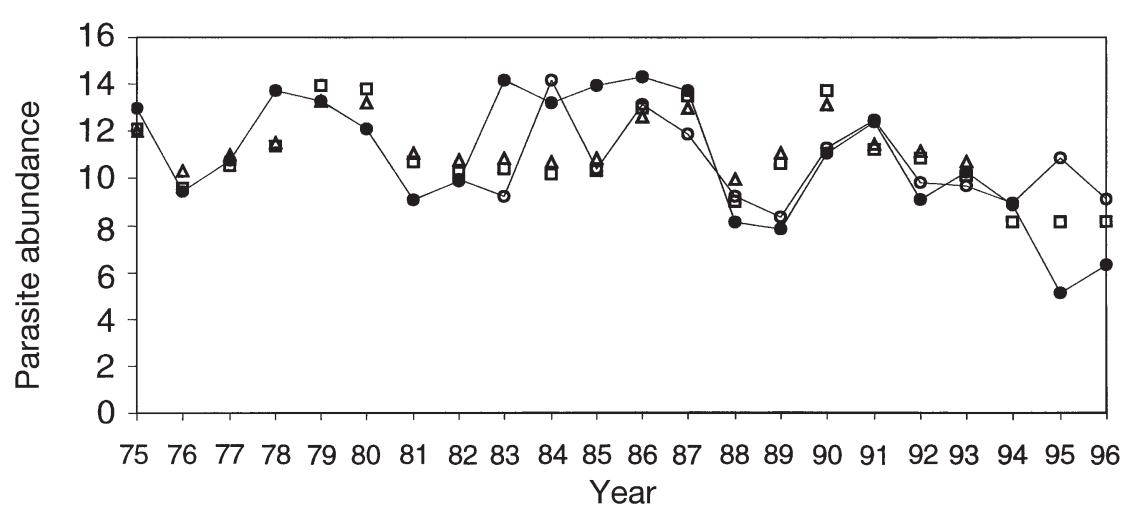

- Observed a Combined model $\Delta$ Sea-ice - o-Temperature

Fig. 6. Observed parasite Kudoa alliaria abundance together with predictions made from a combined multiple regression model using both Signy Island (Location E) sea-ice duration and sea surface temperature at Isla de Fonso (Location B), compared to predictions of simple regressions for sea-ice and sea surface temperature

\section{DISCUSSION}

\section{Parasite dynamics}

Most Micromesistius australis caught in the southwest Atlantic have Kudoa alliaria in their muscle tissue (White Fish Authority 1979). This is likely to affect muscle performance (but see Zawistowski et al. 1986 who found no biochemical change in the muscle) as well as the visual appearance of the flesh which makes the fish more appropriate for processing into surimi than a fillet. Studies by Gaevskaya \& Kovaljova $(1991)^{1}$ in the 1970 s and 1980s suggested infection rates similar to our observations (prevalence 25 to $100 \%$ dependent upon age and catch 
region, fish having between 1 and 65 cysts, cysts being 5 to $25 \times 3$ to $5 \mathrm{~mm}$ in size). Gaevskaya \& Kovaljova $(1991)^{1}$ did not report annual infection differences, supporting our assumption that the significant year effect in our model was an observer effect.

Infection of Micromesistius australis by Kudoa alliaria takes place during the first $1 \frac{1 / 2}{2 r}$ of life. Eggs are spawned in September to October to the southwest of the Falkland Islands, and eggs and larvae are found in the upper pelagic layer around the Islands and towards the Argentine coast (Macchi \& Pájaro 1999). Juveniles become 1 yr of age the following July and between this time and the following July (when they become 2), the existence of parasites becomes apparent in most fish. At this time, the cysts are small (2 to $3 \mathrm{~mm}$ in length in Age 1 fish) and are difficult to see, so infection intensity may be underestimated at these young ages. The rise in infection intensity in Ages 1 to 7 could be explained either by an increase in visibility or multiplication of the parasites before they are fully encapsulated (Moran et al. 1999), or by postulating continuing infection throughout life. The existence of cohort-dependent infection intensity strongly suggests that infection takes place in the very early life stages and well before juveniles recruit to the adult population.

The apparent decline in parasite abundance in older fish might be caused by selective mortality of heavily parasitised fish (Pennycuik 1971, Lester 1984). Although Zawistowski et al. (1986) found no evidence for biochemical changes in the muscle, the swimming ability of older fish may become impaired if they are heavily parasitised. The decline in abundance may alternatively be caused by the low sample sizes of these age-classes.

The variance in parasite abundance is only explained by oceanographic conditions (as indicated by SST). Kudoa abundance appears to bear no relationship to Micromesistius australis population size, despite the wide fluctuations in population size indicated by the VPA. The total stock biomass was about 1.6 million $\mathrm{t}$ in 1978, dropping to $600000 \mathrm{t}$ between 1984 and 1987. This rose to 1 million $t$ in 1993, following the large recruitments centred around the 1990 cohort, and then fell again to its present estimated level of $500000 \mathrm{t}$. None of these changes have been reflected in changes in parasite abundance. The drop in parasite abundance since 1991 initially appears to be coincident with the decline in fish population size, but this only departs from the predictions of the temperature models in the last 2 yr, 1995 and 1996 (Fig. 6). Coincidentally, 1996 was the first year in which $M$. australis stock size (and the estimated parasite population) declined below its previous 1980s low (Fig. 6).

\section{Environmental connectivity with parasite transmission}

One of the most important features of the southern ocean to have been discovered since the advent of satellite derived sea-ice and SST data is the Antarctic Circumpolar Wave (ACW; White \& Peterson 1996). The wave appears as anomalies of atmospheric pressure, wind stress, SST and sea-ice extent with a period of about 4 yr which propagate eastward taking about 8 to $10 \mathrm{yr}$ to circle the pole. It is propagated through water temperatures which retain a memory of the adjacent sea-ice pack from one winter to the next (Gloersen \& White 2001), and is forced by ENSO events from which originate interannual anomalies in SST and precipitable water in the west-central Pacific (Peterson \& White 1998, Cai \& Baines 2001). Even though there is no direct correlation between ENSO and parasite abundance, the apparent coincidence of certain El Niño events and parasite abundance is most likely a reflection of the inter-connected nature of ENSO, the ACW and current systems around South America.

At first sight there would appear to be little physical connection between parasite abundance in a fish that spawns around the Falkland Islands and SST in the northern Drake Passage. However, the migration pattern Micromesistius australis involves spawning in spring to the southwest of the Falkland Islands followed by dispersion to summer feeding grounds around the Falkland Islands, Burdwood Bank and in the Antarctic (Shust 1979, White Fish Authority 1979, Agnew 2002). They are pelagic fish, feeding on large zooplankton such as euphausids (Agnew 2002), including the Antarctic krill Euphausia superba. In the autumn, M. australis congregate in winter feeding concentrations to the south of the South American continent, around Staten Island and over the southern part of the Patagonian shelf where they are fished by the Argentine fleet. They migrate from these areas to their spawning area again in spring. The distribution of $M$. australis therefore covers both coasts of the South American continent, the Drake Passage and Antarctic peninsularSouth Orkney region. M. australis have never been reported from around South Georgia, strongly suggesting that their migration pathway to the Antarctic is directly from South America or the Burdwood Bank.

Records of Micromesistius australis being present around the South Shetland and South Orkney Islands in the summer are common in the 1960s and 1970s, but their occurrence was sporadic (Skora \& Sosinski 1983, Kock 1992, Kellermann 1996). In February 1965, 51 t was caught at depths of 25 to $60 \mathrm{~m}$ by the RV 'Akademic Knipovich' fishing to the north of Laurie Island (South Orkney islands). The fish were closely associated with krill and had been feeding on it. The German 
research cruises of the late 1970s found adults to the north of the South Shetland Islands (Kock 1982). They have not been found in the Antarctic since the early 1980s (K. H. Kock pers. comm.), possibly related to the start of large-scale commercial exploitation on the Patagonian shelf in 1978, but this could also be related to a decline in krill abundance around the Antarctic peninsula since 1982 (Loeb et al. 1997).

The correlation between parasite abundance and SST is strongest for areas immediately south of South America, in the northern part of the Drake Passage, at times when fish are in that area in their winter feeding grounds (Quarter 2, April to May). This is emphasised by the final GLM model of parasite infection intensity, including only age, observation year and temperature at $70^{\circ} \mathrm{W}$ (Quarter 2) which explained as much of the variation as our original model of age, observation year and cohort. There is a real and statistically significant effect of SST on parasite abundance in these fish. In contrast, there is no significant correlation between parasite abundance and temperatures either around Staten Island or the Falkland Islands. This suggests that the oceanographic effects that are important in influencing parasitic infection are those taking place at the time and place of the winter feeding concentrations of Micromesistius australis.

Parasite transmission is thought to be direct (i.e. does not involve an intermediate host) and influenced by patterns of upwelling and water mixing (Kovaljova et al. 1979). Under this model, spores would be released from adults only on consumption by predators, and would then be ingested by larvae or juveniles. This mechanism is consistent with infection that takes place in the first year of life. Micromesistius australis spawn to the southwest of the Falkland Islands in September to October, with the larval otoliths determined as Age 1 after the assumed birth date in July the following year. By the time they are $2 \mathrm{yr}$ old, prevalence of Kudoa in M. australis is more than $70 \%$, suggesting that infection is taking place within 1 or $1 \frac{1 / 2}{\mathrm{yr}}$ of hatching. It also implies that the fish are only susceptible (or primarily susceptible) to infection in this first 11/2 yr of life.

As juveniles, the fish form single-age shoals in shallow water. They have been found over the southern Patagonian shelf and are more common close to the Argentine and Chilean shores than offshore (Ehrlich et al. 1999). Adult distribution may be coincident with these juvenile areas, but is more likely to be farther offshore. The Argentine fishery on winter adults takes place over the $200 \mathrm{~m}$ bathymetric contour (Cousseau \& Perrotta 2000).

The SST/sea-ice/parasite correlation is consistently significant only for environmental conditions in the winter prior to the cohort being spawned, which implies that the parasite density caused by this winter distribution remains as a 'spore field' in the water column until juveniles encounter it over the following year. Adult feeding areas around the southern tip of South America are upstream of juveniles distributed over the Patagonian shelf. Changes in the density of the 'spore field' encountered by juveniles could be affected by environmentally induced changes to the distribution of adults or juveniles, or predators on those adults. The most likely cause is an expansion of the adult feeding range for longer periods in warm years, leading to lower densities of adults around the Staten Island/Drake Passage area, upstream of the juvenile distributions, a lower density 'spore field' and lower parasite abundance in the subsequent cohort. Data on the occurrence of Micromesistius australis in the Antarctic could be used to test this hypothesis. Unfortunately, there are only sporadic records of such occurrences, February 1965 (Basalaev \& Petukhov 1969), January to March 1976, 1978 and 1981 (see Kock 1982, K. H. Kock pers. comm.). Most of these dates are coincident with cohorts of low parasite intensity, but while supportive of the hypothesis, they are not conclusive. Argentine catch data are only available from 1995 onwards, over which there has been a considerable decline in catch per unit effort (Wöhler et al. 2001), and it is not possible to separate this from possible distributional changes.

Our results show that not only are the hosts susceptible only when they are juveniles, but that they carry the signal of the density of a parasite 'spore field' throughout their lives. This signal is revealed in the relative abundance of parasites in different cohorts. Moreover, the signal is correlated with environmental signals (SST and sea-ice distribution) which indicate cyclical changes in environmental conditions in the area in which adult fish undertake their feeding migrations, the northern Drake Passage.

Acknowledgements. The Falkland Islands Southern Blue Whiting parasite study involved the efforts of a large number of observers and scientists in the Falkland Islands. We would like to acknowledge our deep debt of gratitude to them for their work onboard fishing vessels and in the laboratory. The study was supported and encouraged throughout by the Director of Fisheries, John Barton. We would like to thank Paul Brickle, David Middleton, Eric Morgan and Albina Gaevskaya for enlightening discussions about parasite infection mechanisms. Finally, we gratefully acknowledge Eugene Murphy of the British Antarctic Survey who gave us permission to use the Signy Island sea-ice data.

\section{LITERATURE CITED}

Agnew DJ (2002) Critical aspects of the Falkland Islands pelagic ecosystem: distribution, spawning and migration of pelagic animals in relation to oil exploration. Aquat Conserv 12:39-50 
Basalaev VN, Petuchov AG (1969) Experimental poutassou fishing in the Scotia Sea from the research factory ship 'Academician Knipovich'. In: Marty JJ (ed) Marine biological resources of the Antarctic, Vol 60. First expedition of RV 'Academician Knipovich', Trudy All-Union Research Institute of Marine Fisheries and Oceanography, Moscow. Moscow Publishing House Pischevaya Promyshlennost, Moscow, p 307-310 (in Russian)

Bush AO, Lafferty KD, Lotz JM, Shostak AW (1997) Parasitology meets ecology on its own terms: Margolis et al. revisited. J Parasitol 83(4):575-583

Cai W, Baines PG (2001) Forcing of the Antarctic Circumpolar Wave by El Niño-Southern Oscillation teleconnections. J Geophys Res 106:9019-9038

Cordo HD, Wöhler OC (2000) Abundance indices of southern blue whiting (Micromesistius australis) in the Southwest Atlantic. Frente Maritimo 18:125-134

Cousseau MB, Perrotta RG (2000) Peces marinos de Argentina: biología, distribución, pesca. Instituto Nacional de Investigación y Desarrolla Pesquero, Mar del Plata

Csirke J (1987) The Patagonian fishery resources and the offshore fisheries in the South-West Atlantic. FAO Fish Tech Pap 286:75

Ehrlich MD, Sanchez RP, de Ciechomski JD, Machinadiarena L, Pajaro M (1999) Ichthyoplankton composition, distribution and abundance on the Southern Patagonian Shelf and adjacent waters. Documento Cientifico, p 37-65. Instituto Nacional de Investigación y Desarrollo Pesquero, Mar del Plata

FAO (Food and Agriculture Organization) (2000) FAO yearbook. Fishery statistics. Capture production, Vol 90/1. FAO, Rome

Ganowiak ZM (1985) Biological, histochemical and biochemical investigation on rats fed fish meat infested with parasitic protozoa (Kudoa sp). Acta Vet (Beogr) 35:245-252

Gloersen P, White W (2001) Reestablishing the circumpolar wave in sea ice around the Antarctic from one winter to the next. J Geophys Res 106:4391-4395

Grabda J (1978) Studies on parasitic infectation of blue whiting (Micromesistius sp.) with respect to the fish utilization for consumption. Acta Ichthyol Piscatoria 8:29-39

Kalavati C, Brickle P, MacKenzie K (2000) Two new Myxozoan parasites (Myxosporea, Multivalvulida, Bivalvulida) from fishes of the Falkland Islands. Acta Parasitol 45: 285-288

Kellermann AK (1996) Midwater fish ecology. In: Ross RM, Hofmann EE, Langdon BQ (eds) Foundations for ecological research west of the Antarctic Peninsula. Antarct Res Ser, Vol 70. American Geophysical Union, Washington, DC, p 231-256

Kock KH (1982) Fischereibiologische Untersuchungen bei Elephant Island im März 1981. Arch Fischwiss 33 (Suppl 1):127-142

Kock KH (1992) Antarctic fish and fisheries. Studies in polar research. Cambridge University Press, Cambridge

Kovaljova AA, Shulman SS, Yakovlev VN (1979) Myxosporidians of the genus Kudoa (Myxosporidia, Multivalvulea) from the Atlantic Ocean basin. In: Systematics and ecology of sporozoans and knydosporidians. Tr Zool Inst Akad Nauk SSSR 87:42-46

Lester RJG (1984) A review of methods for estimating mortality due to parasites in wild fish populations. Helgol Meeresunters 37:53-64

Loeb V, Siegel V, Holm Hansen O, Hewitt R, Fraser W, Trivelpiece W, Trivelpiece S (1997) Effects of sea-ice extent and krill or salp dominance on the Antarctic food web. Nature 387(6636):897-900

Macchi GJ, Pájaro M (1999) Features of the reproductive biology of the southern blue whiting (Micromesisitus australis). INIDEP Doc Cient 5:67-79

MacKenzie K, Longshaw M (1995) Parasites of the hakes Merluccius australis and Merluccius hubbsi in the waters around the Falkland Islands, Southern Chile and Argentina, with an assessment of their potential value as biological tags. Can J Fish Aquat Sci 52(Suppl 1):213-224

Maravelias CD (1997) Trends in abundance and geographic distribution of North Sea herring in relation to environmental factors. Mar Ecol Prog Ser 159:151-164

Moore JK, Abbott MR, Richman JG (1999) Location and dynamics of the Antarctic Polar Front from satellite sea surface temperature data. J Geophys Res 104:3059-3073

Moran JDW, Whitaker DJ, Kent ML (1999) A review of the Myxosporean genus Kudoa Meglitsch, 1947, and its impact on the international aquaculture industry and commercial fisheries. Aquaculture 172:163-196

Murphy EJ, Clarke A, Symon C, Priddle J (1995) Temporal variation in Antarctic sea-ice: analysis of a long term fastice record from the South Orkney Islands. Deep-Sea Res I 42:1045-1062

Pennycuik L (1971) Differences in the parasite infections in 3-spined sticklebacks (Gasterosteus aculeatus L.) of different sex, age and size. Parasitology 63:407-418

Peterson RG, White WB (1998) Slow oceanic teleconnections linking the Antarctic Circumpolar Wave with the tropical El Niño-Southern Oscillation. J Geophys Res 103: 24573-24583

Ropelewski CF, Jones PD (1987) An extension of the TahitiDarwin Southern Oscillation Index. Mon Weather Rev 115:2161-2165

Sardella NH, Timi JT (1996) Parasite communities of Merluccius hubbsi from the Argentinian-Uruguayan common fishing zone. Fish Res 27:81-88

Shust KV (1978) On the distribution and biology of members of the genus Micromesistius (Gadidae). J Ichthyol 18: 490-493

Skora KE, Sosinski J (1983) Observations on the ichthyofauna distribution in the regions of the Scotia Sea and Antarctic Peninsula. Pol Polar Res 4:49-55

Stefánsson G (1996) Analysis of groundfish survey abundance data: combining the GLM and delta approaches. ICES J Mar Sci 53(3):577-588

Venables WN, Ripley BD (1997) Modern applied statistics with S-Plus, 2nd edn. Springer Verlag, New York

White WB, Peterson RG (1996) An Antarctic circumpolar wave in surface pressure, wind, temperature and sea-ice extent. Nature 380:699-702

White Fish Authority (1979) Fisheries opportunities in the South West Atlantic. Report to the Foreign \& Commonwealth Office, UK on the fish stocks and prospects for exploitation. Foreign \& Commonwealth Office, London

Wöhler OC, Hansen JE, Cassia MC (2000) Southern blue whiting (Micromesistius australis). In: Bezzi S, Akselman $\mathrm{R}_{\text {, }}$ Boschi E (eds) Síntesis del estado de las pesquerías marítimas argentinas y de la Cuenca de Plata. Años 1997-1998, con una actualización de 1999. Spec Publ Instituto Nacional de Investigación y Desarrollo Pesquero, Mar del Plata, p 41-52

Zawistowski S, Czewzyk T, Ganowiak Z (1986) Histochemical investigations of Falkland blue whiting muscles infested with parasitic protozoans of the genus Kudoa sp. Bull Sea Fish Inst Gdynia 17(3/4):33-35 